\title{
Performance evaluation of the variable refrigerant flow (VRF) air-conditioning system during the heating-defrosting cyclic operation
}

\author{
Napoleon ENTERIA***, Hideki YAMAGUCHI***, Masato MIYATA***, \\ Takao SAWACHI* and Yasuo KUWASAWA*** \\ *Building Research Institute \\ 1 Tachihara, Tsukuba City 305-0802, Ibaraki, Japan \\ ** lligan Institute of Technology of the Mindanao State University \\ Tibanga, lligan City 9200, Lanao Del Norte, Philippines \\ E-mail: napoleon@kenken.go.jp \\ *** National Institute for Land and Infrastructure Management \\ 1 Tachihara, Tsukuba City 305-0802, Ibaraki, Japan
}

Received: 13 May 2017; Revised: 29 September 2017; Accepted: 7 November 2017

\begin{abstract}
This paper shows the performance evaluation of the variable refrigerant flow (VRF) air-conditioning system subjected to very low outdoor air temperature at which the heating-defrosting cyclic operation occurred. The objectives of the study are to know the effect of the heating-defrosting cyclic operation in the VRF airconditioning performances and of the indoor environment thermal conditions. The one outdoor unit's and two indoor units' VRF air-conditioning system was used as a test specimen in the controlled testing chambers in which temperature and humidity were controlled. Several test cases were done covering from constant dry bulb temperature with different wet bulb temperature and for both dry bulb temperature and wet bulb temperature different. The results of the study show that the heating-defrosting cyclic operation affected the performance of the VRF air-conditioning system. It shows that the heating time changes depend on both dry bulb and wet bulb temperatures. It shows that the defrosting time is almost the same for different dry bulb and wet bulb temperatures for different heating times. The cyclic heating-defrosting operation affected the indoor air temperature by lowering the indoor air temperature during defrosting. Based on the results, necessary measures are needed to address the effect of the defrosting in the VRF air-conditioning system performance and of the indoor thermal environment conditions. The heating-defrosting cyclic operation is expected to occur when the VRF airconditioning system is installed in an actual building in a temperate climate, and in the performance evaluation of the different VRF air-conditioning systems under these conditions, it is important to know how it affects the system's operation behavior, energy consumption and support of the indoor environment thermal conditions.
\end{abstract}

Keywords : Air-conditioning system, Variable refrigerant flow, Thermal loading, Energy consumption, Heating-defrosting cycle

\section{Introduction}

The maintenance of the building's indoor comfortable thermal environment and air quality during the coldest part of the winter season is very important for the occupants. In advanced and highly developed countries, the application of the heating, ventilating and air-conditioning (HVAC) system is a norm in any built environment to cater to the needs of the occupants. There are many kinds of HVAC systems installed in different built environments, such as buildings and houses, to support the needed indoor thermal environment requirement. As the concern of energy consumption related to the maintenance of indoor environmental conditions is one of the most important issues in reducing a building's energy consumption, the application of the most energy efficient HVAC system is a trend. In Japan, the determination of planned 
new buildings or for retrofitted existing buildings need proper estimation of energy consumption based on the new regulations of building energy standards (Building Energy Standard of Japan, 2013).

The VRF air-conditioning system is one of the HVAC systems which is widely installed globally due to its high energy efficiency in different operational conditions such as partial loading, changing loading pattern and other features (Goetzler, 2007). Normally, the evaluation of any HVAC system such as that of the VRF air-conditioning system follows the evaluation standards set by different standard evaluation bodies such as the Japan Industrial Standards (JIS, 2015). As expected, in the evaluation standards, the VRF air-conditioning system under performance evaluation is operated at steady conditions with controlled external conditions such as loading, air temperature and humidity as it is much simpler and easier. However, as the VRF air-conditioning system is to be installed in actual buildings or houses in which real operation is expected to depend on outdoor and indoor environmental conditions, the evaluation of the VRF airconditioning system based on the possible real operational conditions is very important.

The VRF air-conditioning system utilizes the variable speed electric motor using an inverter to drive the compressor. The main advantage of using the variable speed drive compared to a constant drive is that the refrigerant flow rate varies depending on the thermal loading. Coupled with the electronic expansion valve (EEV) to regulate the refrigerant flow, the indoor temperature setting can be smoothly maintained. As the compressor speed varies due to the change of the electric motor speed, the electric power consumption varies as well. Hence, by using the variable speed operated compressor, the electric power consumption is lowered compared to the constant speed, particularly for a partial thermal load and of changing thermal loading. In addition, for a VRF air-conditioning system intended for locations with a winter, the four-way valve changes the direction of the refrigerant flow for the heating or cooling mode, thus one air-conditioning system serves both purposes.

As the application and usage of the VRF air-conditioning system increases due to its popularity in terms of flexibility in operation, the more an accurate estimate of its actual electric energy consumption becomes important for incorporation in the estimation of the building energy consumption both for new and for retrofit buildings (Building Energy Standard of Japan, 2013). As the VRF air-conditioning system is expected to encounter heating mode operation in locations with a winter season, the performance evaluation of the system in this climatic condition is important. The review of the previous studies shows that the evaluation of the VRF air-conditioning system occurring during the heating-defrosting cyclic operation has not yet been done in detail (Enteria et al., 2016a; Enteria et al., 2016b; Horie and Hihara, 2012; Watanabe et al., 2009; Watanabe et al., 2007).

This paper shows the evaluation of the VRF air-conditioning system with one outdoor unit and two indoor units operated under different very low outdoor dry bulb temperatures and different wet bulb temperatures in which ice accumulation occurred in the outdoor unit heat exchanger. The results of this study are important in the determination of the actual VRF air-conditioning system's behavior and performance. The contents of this study show how the heatingdefrosting cyclic operation affected the indoor thermal environment conditions. Hence, this paper presents results which can be added for a more accurate determination of the electric consumption of the VRF air-conditioning system in the evaluation of the energy consumption of new or retrofitted buildings.

\section{Methodology \\ 2.1 Test facilities}

Figure 1a shows the technical diagram of the testing facilities used to make the performance evaluation of the VRF air-conditioning system presented in this paper. Figure $1 \mathrm{~b}$ shows the actual view of the testing facilities. The testing facilities consist of one outdoor chamber and three indoor chambers. The outdoor chamber can support the system with an outdoor capacity of from $0.33 \mathrm{~kW}$ to $56 \mathrm{~kW}$. The outdoor chamber dry bulb (DB) temperature can be varied from $20^{\circ} \mathrm{C}$ to $45^{\circ} \mathrm{C}$. The relative humidity range can be varied from $30 \%$ to $80 \%$, controlled by using a wet bulb temperature sensor for the outdoor temperature when it is above the freezing point of water. The three indoor chambers can simulate both cooling and heating loads. The two smaller indoor chambers (Indoor Chamber $1 \& 2$ ) can support a heating load of up to $12 \mathrm{~kW}$ with humidification capability while the bigger indoor chamber (Indoor Chamber 3 ) can support a heating load of up to $24 \mathrm{~kW}$ with humidification capability. Both indoor chambers 1 and 2 can support a cooling load of up to $12.5 \mathrm{~kW}$, and indoor chamber 3 can support a cooling load of up to $25 \mathrm{~kW}$; the two indoor units can be installed in tandem for the case of indoor chamber 3. In this study, indoor chambers 1 and 2 are used as the VRF air-conditioning system utilizing two indoor units in separate indoor chambers. Control and monitoring devices are installed to gather the needed 


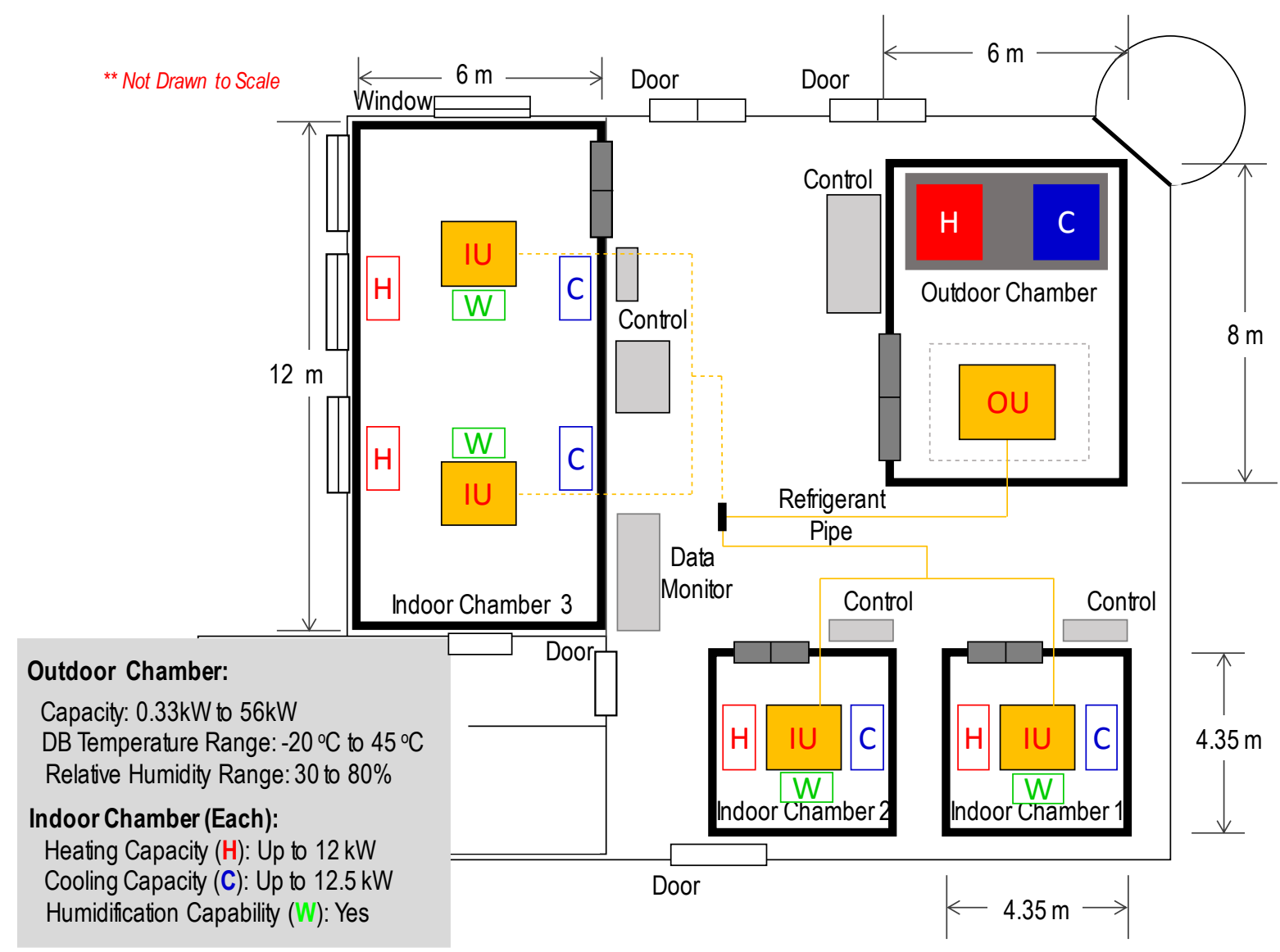

a)

Outdoor Chamber

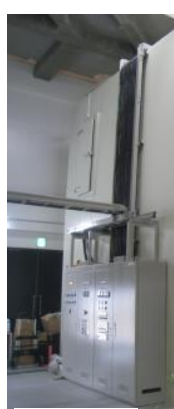

Outside View b)

Fig. 1. Testing controlled chambers: a) schematic diagram, and; b) actual view.
Indoor Chamber

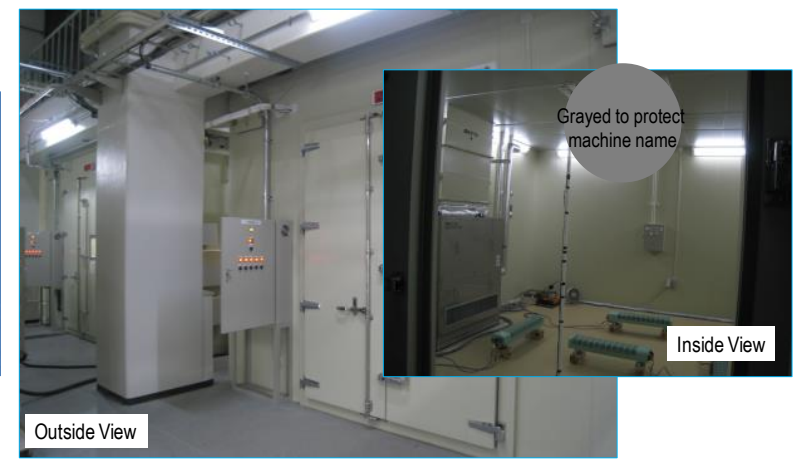

parameters.

\subsection{Test specimen}

Figure 2 shows the schematic diagram of the installed VRF air-conditioning system with R410A as refrigerant in controlled chambers. The outdoor unit is installed in the outdoor controlled chamber (See Figure 1) in which the air temperature and humidity are set to prescribed values. The indoor units are installed in the two separated indoor chambers - Indoor Chamber $1 \& 2$ (See Figure 1), in which air temperature and humidity are controlled based on the required values. The VRF air-conditioning system's outdoor and indoor units are connected using the specified refrigerant piping and insulation. There are several sensors attached to the system such as the electric power meter to measure the electric power consumption of the outdoor and indoor units. Refrigerant flow meters are installed in the refrigerant piping to measure the refrigerant flow rates as presented in the diagram. Refrigerant absolute pressure sensors are installed in the 


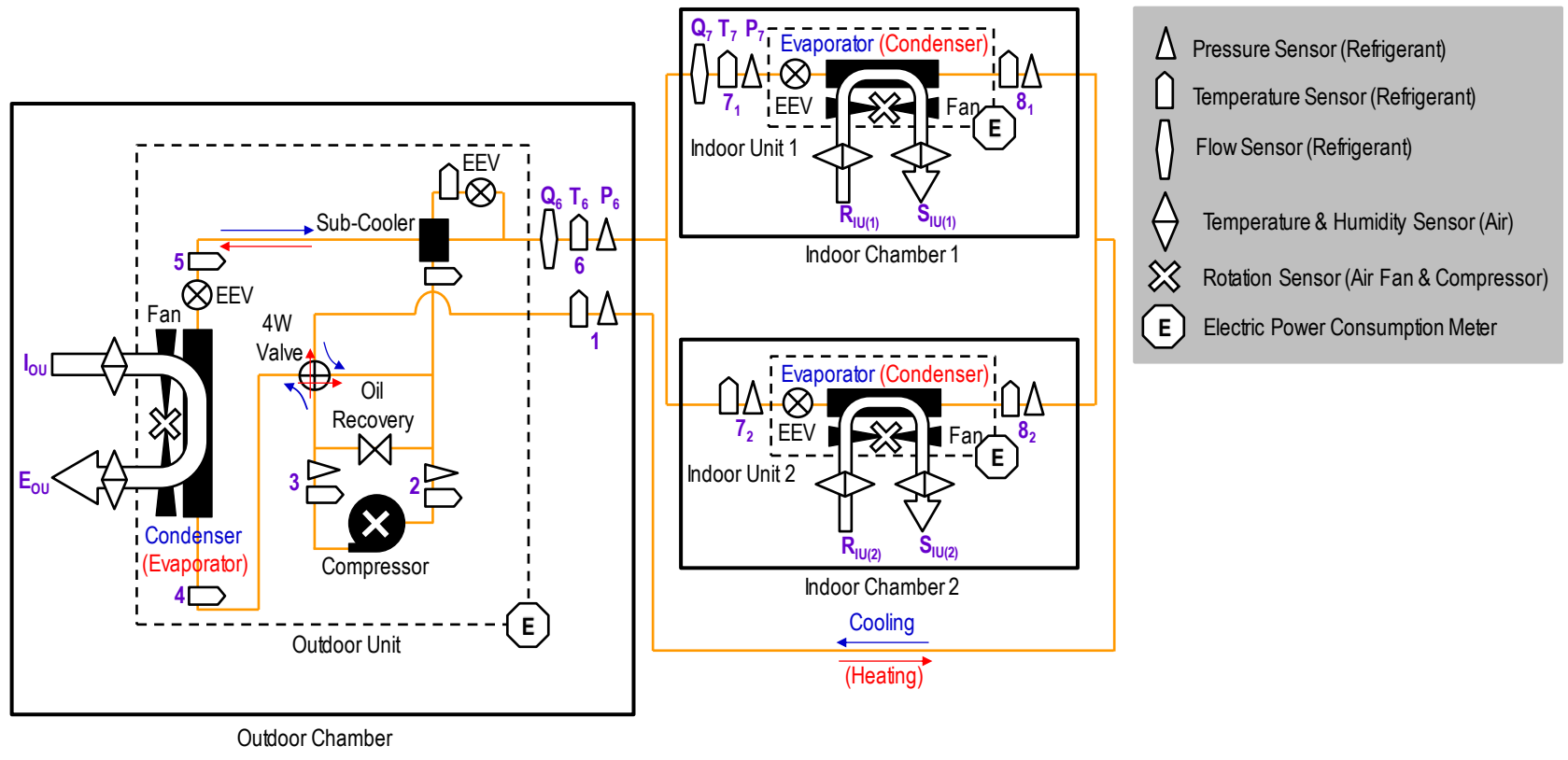

Fig. 2. Schematic diagram of the single outdoor unit and double indoor units' VRF air-conditioning system.

Table 1 Specified values of the VRF air-conditioning system in the study.

\begin{tabular}{ccc}
\hline Operation Mode & Rated & Rated \\
& Electric Consumption, $\mathrm{kW}$ & Capacity, $\mathrm{kW}$ \\
\hline Cooling & 6.61 & 22.4 \\
Heating & 6.43 & 25 \\
\hline
\end{tabular}

different locations in the refrigerant piping network to measure the pressure of the refrigerant. Refrigerant temperature sensors attached to the surface of the tube covered with insulation measured the different temperatures of the refrigerant as shown in the diagram. Air temperatures and humidity sensors are installed in both the outdoor and indoor units to measure the air properties. Rotation sensors are installed for the measurement of rotation of the compressor, outdoor air fan and indoor air fans. Table 1 shows the rated values of the VRF air-conditioning system used in this study. The presented values are based on the catalogue values for the VRF air-conditioning system provided for by the manufacturer.

\subsection{Test cases}

Table 2 shows the conditions for test cases used to measure the performance of the VRF air-conditioning system when subjected to low outdoor air dry bulb temperatures and wet bulb temperatures while the system is operating in heating mode in which the heating-defrosting cyclic operation occurred. Test Group 1 shows the condition in which the outdoor air dry bulb temperatures are the same with different wet bulb temperatures, the purpose of which is to understand how the different outdoor wet bulb temperature affects the system operation and performance. Test Group 2 shows the evaluation of the system based on the different outdoor dry bulb and wet bulb temperatures. The purpose of the test group is to understand the behavior and performance of the system when the outdoor temperature (DBT and WBT) changes. Figure 3 shows the equivalent humidity ratio or the moisture of the air for the different conditions shown in Test Group 1 and Test Group 2 test cases presented in Table 2. The table shows that for Test Group 1, the amount of moisture in the air reduced from around $4 \mathrm{~g} / \mathrm{kg}$ to less than $3.5 \mathrm{~g} / \mathrm{kg}$; For Test Group 2, the amount of moisture in the air reduced from around $2.5 \mathrm{~g} / \mathrm{kg}$ to almost $0.5 \mathrm{~g} / \mathrm{kg}$.

In the performance evaluation shown in this paper, the $100 \%$ loading is applied to the VRF air-conditioning system in which both two indoor units are operating at full capacity for different test conditions shown in Table 2 . The $100 \%$ loading is based on the rated heating capacity shown in Table 1. The load balance ratio $(\alpha)$ is shown in Eq. (1) (Enteria et al., 2016b). In this measurement evaluation, $\alpha$ is equal to 1 , the indoor chamber 1 load is equal to the indoor chamber 
Table 2 Test cases for the measurement of the single outdoor unit and double indoor units' VRF air-conditioning system.

\begin{tabular}{|c|c|c|c|c|}
\hline Test Group & $\begin{array}{l}\text { Outdoor Conditions, }{ }^{\circ} \mathrm{C} \\
\text { (Outdoor Chamber) }\end{array}$ & $\begin{array}{c}\text { Indoor Conditions, }{ }^{\circ} \mathrm{C} \\
\text { (Indoor Chamber) }\end{array}$ & $\begin{array}{c}\text { Percentage Loading, \% } \\
\text { (Respect to Rated Load, Table 1) }\end{array}$ & $\begin{array}{c}\text { Load Balance Ratio, } \alpha \\
\text { (Ratio of Indoor Units Load) }\end{array}$ \\
\hline & $2^{\circ} \mathrm{C}$ DBT \& $1.5^{\circ} \mathrm{C}$ WBT & & & \\
\hline \multirow[t]{4}{*}{ Group 1} & $2^{\circ} \mathrm{C}$ DBT \& $1^{\circ} \mathrm{C}$ WBT & $20^{\circ} \mathrm{C} \mathrm{DBT}$ & 100 & 1 \\
\hline & $2^{\circ} \mathrm{C}$ DBT \& $0.5^{\circ} \mathrm{C}$ WBT & & & \\
\hline & $-3^{\circ} \mathrm{C}$ DBT \& $-4^{\circ} \mathrm{C}$ WBT & & & \\
\hline & $-5^{\circ} \mathrm{C}$ DBT \& $-6^{\circ} \mathrm{C}$ WBT & & & \\
\hline \multirow[t]{3}{*}{ Group 2} & $-7^{\circ} \mathrm{C}$ DBT \& $-8^{\circ} \mathrm{C}$ WBT & $20^{\circ} \mathrm{C} \mathrm{DBT}$ & 100 & 1 \\
\hline & $-11^{\circ} \mathrm{C}$ DBT \& $-12^{\circ} \mathrm{C}$ WBT & & & \\
\hline & $-15^{\circ} \mathrm{C}$ DBT \& $-16^{\circ} \mathrm{C}$ WBT & & & \\
\hline
\end{tabular}

a)
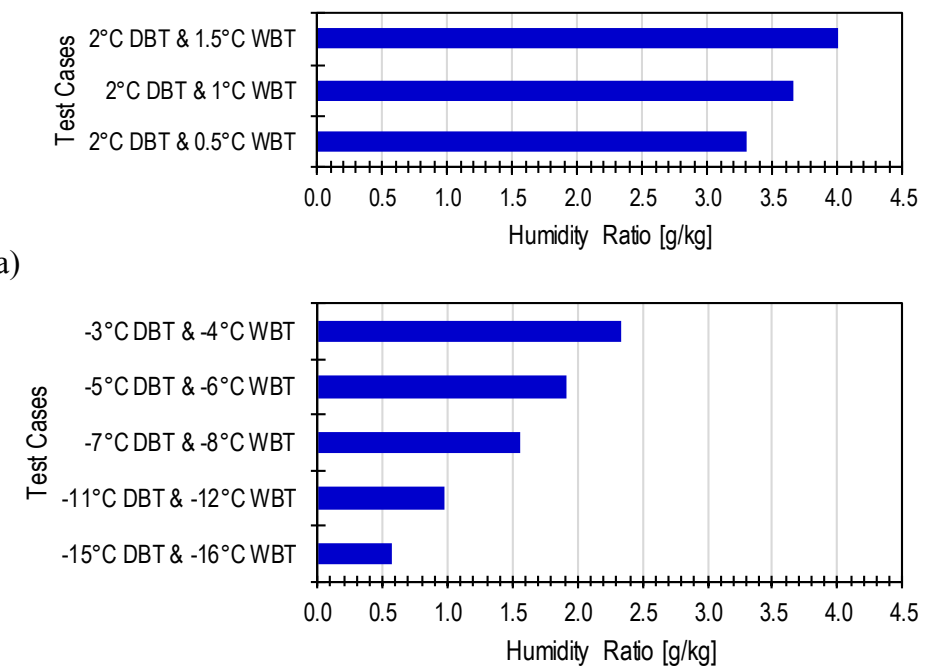

b)

Fig. 3. Equivalent humidity ratio for the different outdoor air conditions, Table 2: a) Group 1: Constant dry bulb temperature and different wet bulb temperature, and; b) Group 2: Different dry bulb temperature and wet bulb temperature.

2 load. Only balanced loading is covered in this study which the heating-defrosting cyclic operation occurred. An unbalanced loading during the heating mode is presented in our previous study (Enteria et al., 2016b).

$$
\alpha=\frac{\dot{Q_{I C_{1}}}}{\dot{Q_{I C_{2}}}}=1 ; \dot{Q}_{I C_{1}}=\dot{Q}_{I C_{2}}
$$

\subsection{Test evaluation}

Figure 4 shows the representative heating-defrosting cyclic operation of the VRF air-conditioning system. The heating capacity of the system is determined when the system heats up the indoor chambers to support the set-point temperature which in this case is at $20^{\circ} \mathrm{C}$. As the ice formation occurring in the outdoor unit heat exchanger becomes heavy enough to affect the system performance, the system's control logic kicks in to start the defrosting to melt the accumulated ice in the outdoor heat exchanger. During defrosting, no heating of the indoor chambers occurs as the system is simply in a cooling mode operation and the system's air fans are not operating (outdoor unit and indoor units): the outdoor air fan does not operate so as to maximize the transfer of heat from the refrigerant to the ice to melt it while the indoor air fans are not operating so as to minimize the absorption of heat from the indoor air to the refrigerant and not cause further cooling to indoor chambers. During the heating-defrosting cyclic operation, the compressor is operating 


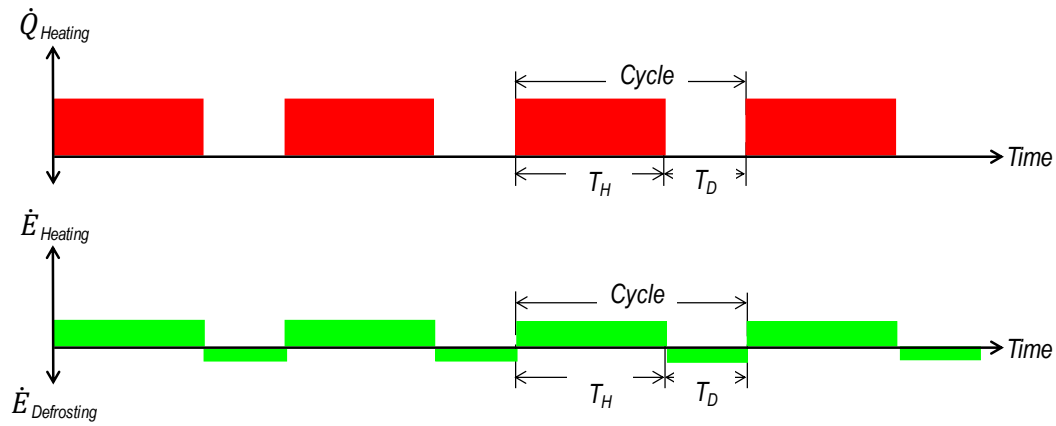

Fig. 4. Calculation of the VRF air-conditioning system actual coefficient of performance during the heating-defrosting cyclic operation.

to move the refrigerant between the outdoor unit and the indoor units which the four-way valve controls where the refrigerant flow passes first after the compressor. In the case of the heating operation, the refrigerant after the compressor flows first to indoor units to release the heat absorbed by the refrigerant from the outdoor chamber air and the compressor. In the defrosting operation, the refrigerant after the compressor flows first to the outdoor heat exchanger to release the heat absorbed from the indoor air to melt the accumulated ice in the outdoor unit heat exchanger.

The calculation of the VRF air-conditioning system heating capacity in this study is based on the moist air enthalpy difference between the return air and the supply air in the indoor units, multiplied by the air flow rate. The air flow rate calculation is based on the obtained correlation of the indoor units' air fan speed to the air volumetric flow rates from a separate measurement. The electric energy consumption is based on the outdoor unit's power consumption. The indoor units' electric power consumption is not considered in the calculation of the coefficient of performance, which is intended to compare the actual power consumption with respect to the rated electric power consumption shown in Table 1 . It is noted here that the electric power consumption of the indoor unit is minimal, less than $40 \mathrm{~W}$ each. Equation (2) shows the calculation of the coefficient of performance as shown in Fig. 4. It is noted that during defrosting the indoor unit air fans stopped, thus the $\dot{Q}_{\text {Defrosting }}$ is zero. However, as during the defrosting operation, the compressor operates to move the refrigerant, and the electric consumption is measured.

$$
C O P=\frac{\frac{1}{n} \sum_{\text {Time }_{\text {Cycle }}}^{n}\left(\dot{Q}_{\text {Heating }}+\dot{Q}_{\text {Defrosting }}\right)}{\frac{1}{n} \sum_{\text {Time }_{\text {Cycle }}}^{n}\left(\dot{E}_{\text {Heating }}+\dot{E}_{\text {Defrosting }}\right)}
$$

\section{Results and discussion}

\subsection{Instantaneous data}

\subsubsection{Same outdoor chamber air DBT and different outdoor chamber air WBT}

Figures 5, 6 and 7 show the instantaneous results of the compressor speed, outdoor unit electric consumption, heating capacity and indoor chambers' air temperatures and humidity. The indoor chamber humidity is not controlled in this study as presented in Table 2 for test cases conditions. The results show the heating-defrosting cyclic operation which during the start of one cycle, in which the four-way valve changed the opening, the system gradually starts to produce heat to condition the indoor chambers (red line) which the compressor operates (green line) and the corresponding electric energy consumed as presented in graphs a of Figs. 5, 6 and 7. The four-way valve changes the valve opening after the end of the heating operation to start the defrosting operation in which the compressor is stopped. Once the valve is in position for the defrosting operation, the compressor starts to operate as presented in the results. As shown, the compressor electric consumption when the system is operating in heating and defrosting operations is different even with almost the same compressor speed. The difference in electric consumption for heating and defrosting operations is due to the refrigerant pressure difference in the heating and defrosting operation, to be shown in succeeding graphs. During the start of the heating operation, the indoor set-point temperature starts to be attained at $20^{\circ} \mathrm{C}$ (See IU RA Temp). The data is based on the return air temperature shown in Figs. 5, 6 and 7 for graphs b and c. However, during the 


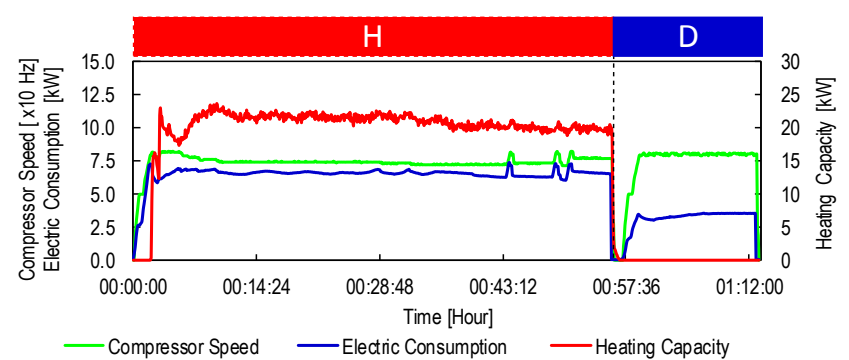

a)

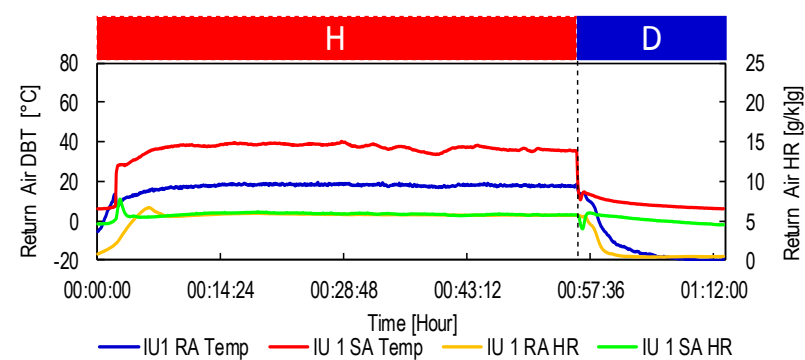

b)

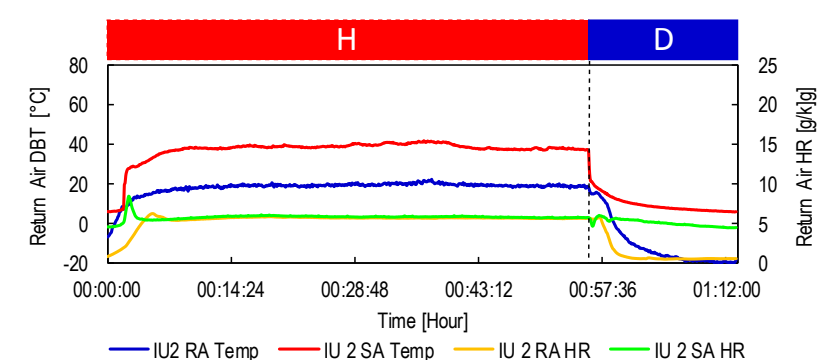

c)

Fig. 5. Results at $2^{\circ} \mathrm{C} \mathrm{DBT}$ and $1.5^{\circ} \mathrm{C}$ WBT (H: Heating; D: Defrosting): a) Compressor speed, electric consumption and heating capacity; b) Indoor chamber 1 dry bulb temperature and humidity ratio, and; c) Indoor chamber 2 dry bulb temperature and humidity ratio.

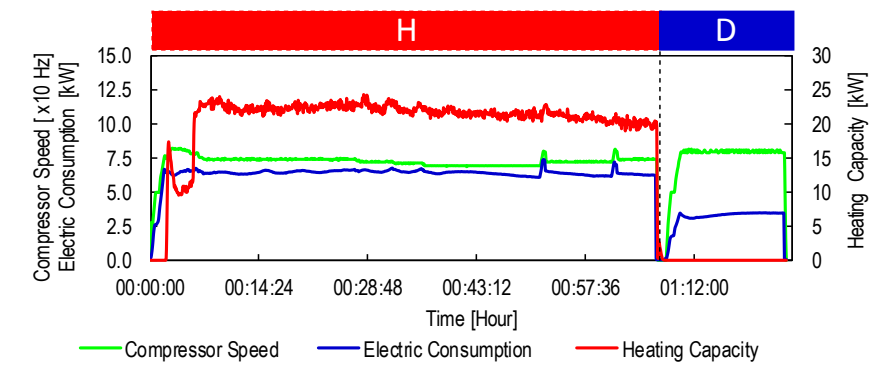

a)

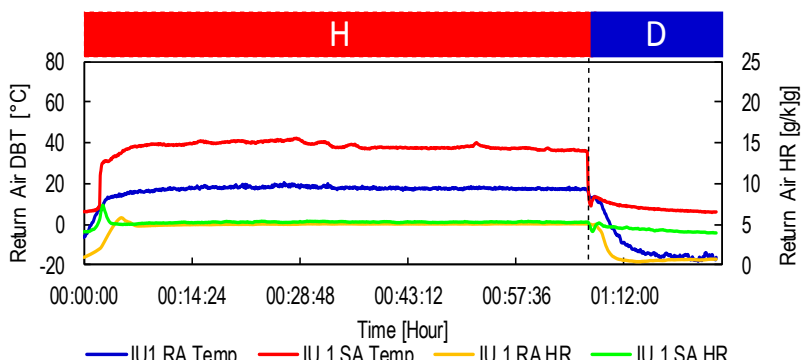

b)

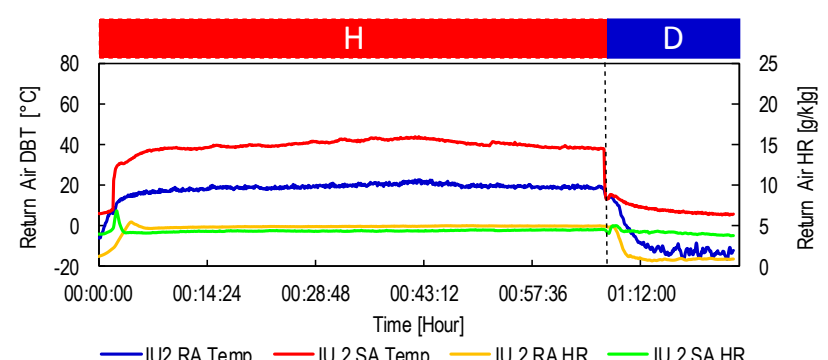

c)

Fig. 6. Results at $2^{\circ} \mathrm{C}$ DBT and $1^{\circ} \mathrm{C}$ WBT (H: Heating; D: Defrosting): a) Compressor speed, electric consumption and heating capacity; b) Indoor chamber 1 dry bulb temperature and humidity ratio, and; c) Indoor chamber 2 dry bulb temperature and humidity ratio.

defrosting operation, the indoor chambers' air temperature suddenly decreases due to the reverse of VRF air-conditioning operation to defrosting which is a cooling operation except that the air fans stopped to keep the cold draft air from circulating in the indoor chambers. With this operation (defrosting), the indoor unit heat exchangers are in the process of absorbing heat from the indoor chamber air; thus, the temperature of the air is very low near the indoor units' air entrance and exit. As cold air density is higher, the cold air near the indoor unit heat exchanger gradually goes down, resulting in the measurement of cold air temperature both in the return air and supply air during the defrosting operation. In the actual 


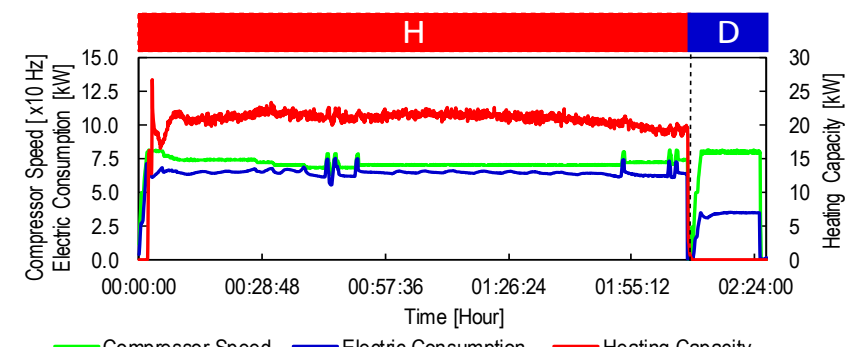

a)

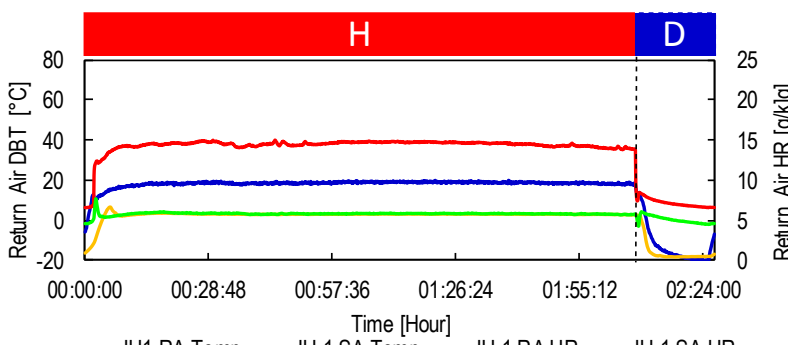

b)

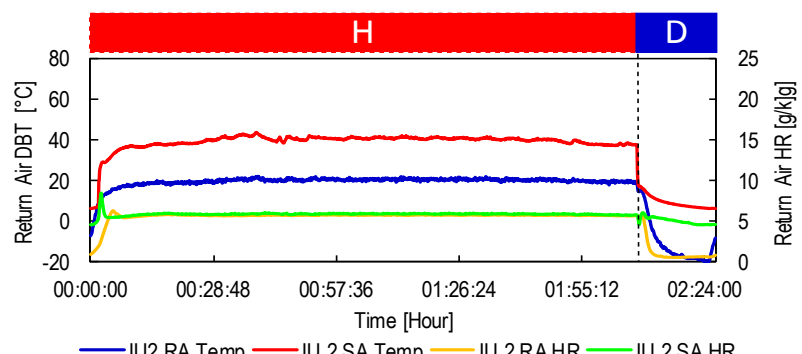

c)

Fig. 7. Results at $2{ }^{\circ} \mathrm{C}$ DBT and $0.5^{\circ} \mathrm{C}$ WBT (H: Heating; D: Defrosting): a) Compressor speed, electric consumption and heating capacity; b) Indoor chamber 1 dry bulb temperature and humidity ratio, and; c) Indoor chamber 2 dry bulb temperature and humidity ratio.

situation (real buildings and houses), the defrosting operation might affect the indoor thermal environment, particularly for an indoor environment with no back-up heater, low thermal insulation or/with very low outdoor air temperature.

During the heating-defrosting cyclic operation of the system at a different outdoor air wet bulb temperature for the same dry bulb temperature, the results show the different time span of the heating operation before the defrosting operation kicks in. In different VRF air-conditioning systems, a different logic is used to kick in the defrosting operation with the same purpose of proper detection of ice accumulation in the outdoor unit heat exchanger in which the ice accumulation affected the effectiveness of the heat transfer between the outdoor chamber air and the refrigerant passing through the outdoor unit heat exchanger. The accumulation of ice in the outdoor heat exchanger increases the heat transfer resistance between the air and the refrigerant, and at the same time blocks the air that is to be sucked in by the outdoor unit air fan. Hence, defrosting or melting the accumulated ice in the outdoor unit heat exchanger at the most efficient and minimum time is important so as to maximize the usage of the outdoor unit heat exchanger during the heating operation, and at the same time not sacrifice the indoor thermal environment condition during the defrosting operation. As a different wet bulb temperature for the same dry bulb temperature has a different moisture content of air as shown in Fig. 3, it is expected that when the moisture in the air is high for the same dry bulb temperature, the accumulation of ice or ice formation in the outdoor heat exchanger occurs at a faster rate for the air with higher moisture content even with the same dry bulb temperature; thus, the time span for the heating operation is shorter before the defrosting operation kicks in. As the accumulation of ice in the outdoor unit heat exchanger is expected to be almost the same for a different outdoor air wet bulb temperature for the same dry bulb temperature due to the different time span of heating operation, the defrosting operation time span is almost the same as shown in the results. Hence, the VRF air-conditioning system in this study operates at a different time span of the heating operation with almost the same time span for the defrosting operation.

\subsubsection{Different outdoor chamber air DBT and WBT}

Figures 8 to 12 show the heating-defrosting cyclic operation of the VRF air-conditioning system when subjected to different outdoor air dry bulb temperatures and wet bulb temperatures (See Table 2). Figures 8a to 12a show the system compressor speed, outdoor unit electric consumption and the heating capacity for the different outdoor air conditions presented in the table (Table 2). As presented in the results, the VRF air-conditioning system produced heat for the indoor chambers once the start of the heating operation kicks in as the compressor speed suddenly increases. Once the heating 


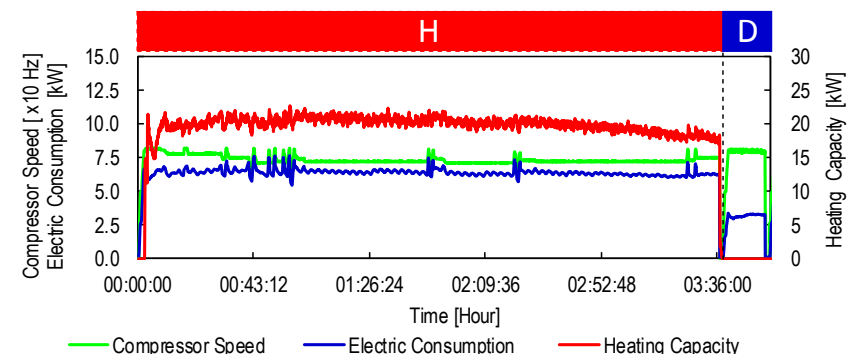

a)

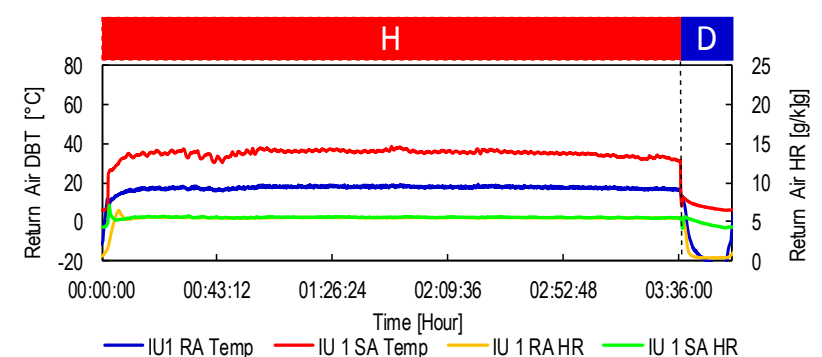

b)

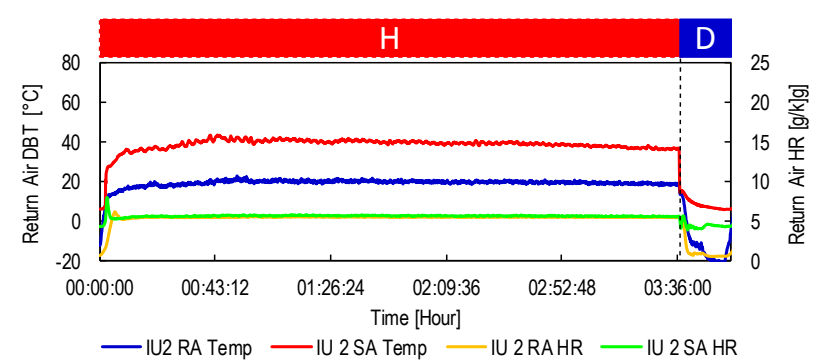

c)

Fig. 8. Results at $-3^{\circ} \mathrm{C}$ DBT and $-4^{\circ} \mathrm{C}$ WBT (H: Heating; D: Defrosting): a) Compressor speed, electric consumption and heating capacity; b) Indoor chamber 1 dry bulb temperature and humidity ratio, and; c) Indoor chamber 2 dry bulb temperature and humidity ratio.

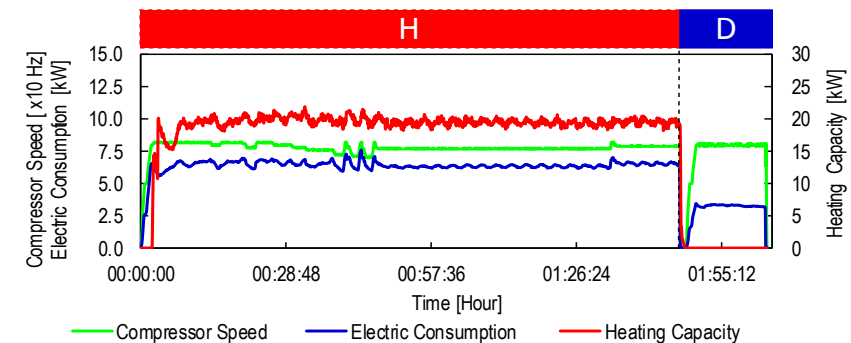

a)

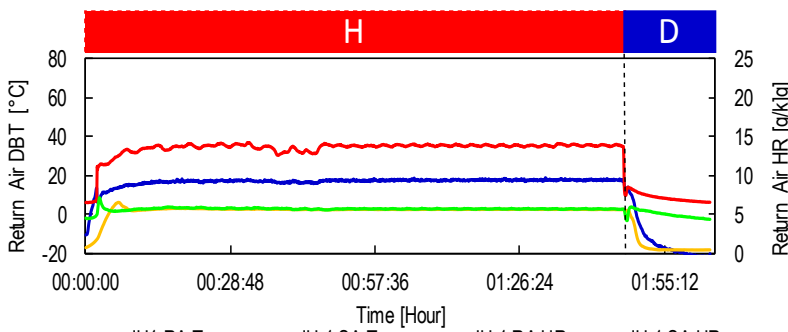

b)

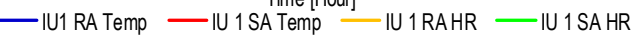

Fig. 9. Results at $-5^{\circ} \mathrm{C}$ DBT and $-6^{\circ} \mathrm{C}$ WBT (H: Heating; D: Defrosting): a) Compressor speed, electric consumption and heating capacity; b) Indoor chamber 1 dry bulb temperature and humidity ratio, and; c) Indoor chamber 2 dry bulb temperature and humidity ratio.

operation finishes due to the ice accumulation in the outdoor heat exchanger which the control logic commands to start the defrosting operation, the compressor stops and the four-way valve turns before the defrosting operation. As the valve is ready for the defrosting operation, the compressor operates again. As presented, the electric energy consumption during the defrosting operation is lower than that of the heating operation for the results. The lower electric consumption during the defrosting operation is due to the lower pressure difference occurred in the defrosting operation compared to the heating operation as explained in Section 3.1.1. 
During the heating operation, the outdoor unit heat exchanger with accumulated ice needs to be thawed out for it to be able to absorb heat from the outdoor chamber air for the heating operation. During the defrosting operation, in the indoor unit heat exchangers, the refrigerant passing through them absorbs the heat from the indoor chambers' air to be released and heat up the outdoor heat exchanger with accumulated ice. The transfer of heat from the high pressure and temperature refrigerant to the ice formation in the outdoor unit heat exchanger melts the ice is an efficient heat transfer compared with no ice formation while the absorption of heat in the indoor chamber air by the low-pressure refrigerant with the indoor chamber with temperature of around $20^{\circ} \mathrm{C}$ is more effective than with air of a much lower air temperature. With this, the pressure difference between the refrigerant during the heating operation and defrosting operation is different: the heating operation has a higher refrigerant pressure difference than that of the defrosting operation. As presented in the results, as the outdoor air temperature decreases, the instantaneous heating capacity decreases as shown in the results of Fig. 8a as compared to Figs. 9a to 12a. The situation of decreasing heating capacity as the outdoor air temperature decreases is due to the increasing difficulty in absorbing heat in the outdoor chamber air to the refrigerant. As the outdoor air temperature decreases, it is expected that the refrigerant pressure passing to the outdoor heat exchanger will decrease as well to decrease the boiling temperature of the refrigerant. However, the system has a limit in its capability to further reduce the refrigerant pressure as the compressor capacity has a limit as does the EEV opening and closing. Coupled with the gradual accumulation of ice in the outdoor heat exchanger, the heat transfer resistance increases.

Figures $9 \mathrm{~b}$ and $9 \mathrm{c}$ to Fig. $12 \mathrm{~b}$ and $12 \mathrm{c}$ show the air temperature and humidity in the indoor chambers. As presented in the results, as the heating operation starts, the temperature in the indoor chambers (See IU RA Temp) tend to approach the set point temperature of $20^{\circ} \mathrm{C}$ until the end of the heating operation. Once the defrosting operation starts, the temperature of the indoor chambers suddenly drops due to the reversal of the indoor unit as a refrigerant evaporator in which the heat in the indoor chamber air is absorbed to support the ice thawing process in the outdoor unit heat exchanger. The decrease of the indoor chambers' air temperatures might affect the indoor thermal environment in an actual application of the system in case no back-up heater is provided, particularly for buildings with low thermal insulation and very low outdoor temperature as explained in Section 3.1.1.

As observed in the results of the indoor chamber temperature (return air temperature), as the outdoor air temperature decreases, with the same set-point temperature of $20^{\circ} \mathrm{C}$, the temperature difference between the set-point temperature and the return air temperature increases (See IU RA Temp). The increasing difference of set-point temperature and the

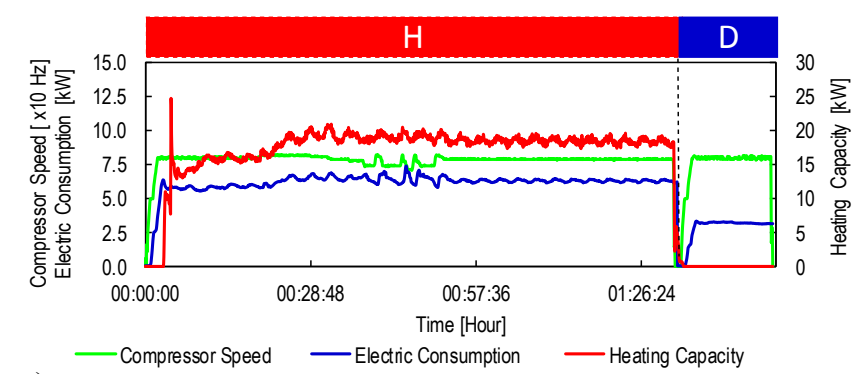

a)

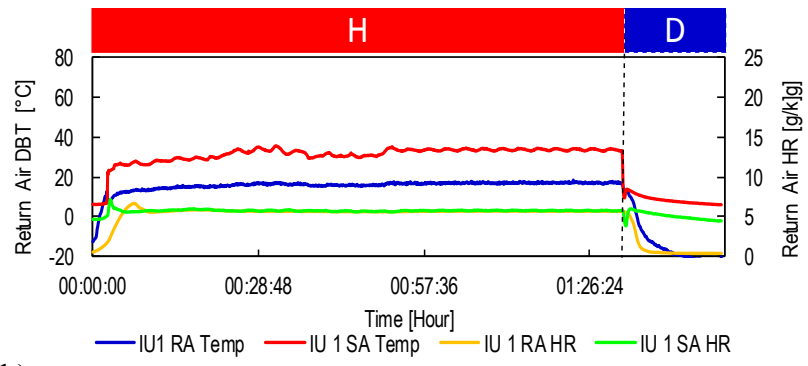

b)

Fig. 10. Results at $-7^{\circ} \mathrm{C}$ DBT and $-8^{\circ} \mathrm{C}$ WBT (H: Heating; D: Defrosting): a) Compressor speed, electric consumption and heating capacity; b) Indoor chamber 1 dry bulb temperature and humidity ratio, and; c) Indoor chamber 2 dry bulb temperature and humidity ratio. 


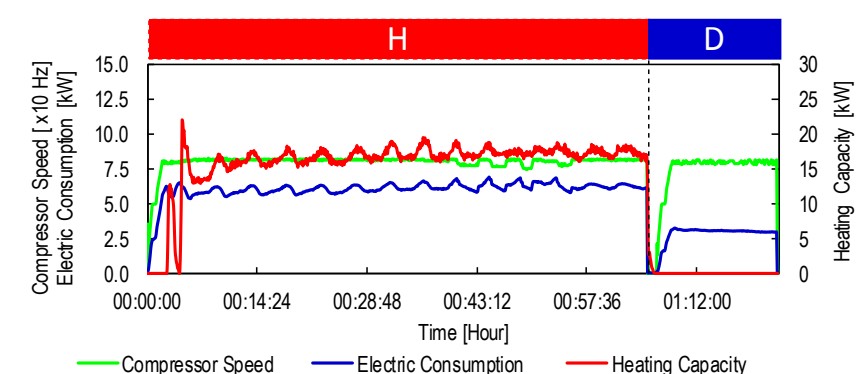

a)

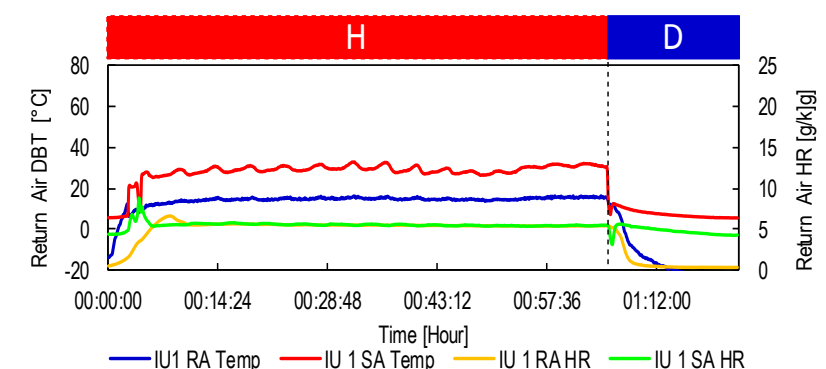

b)

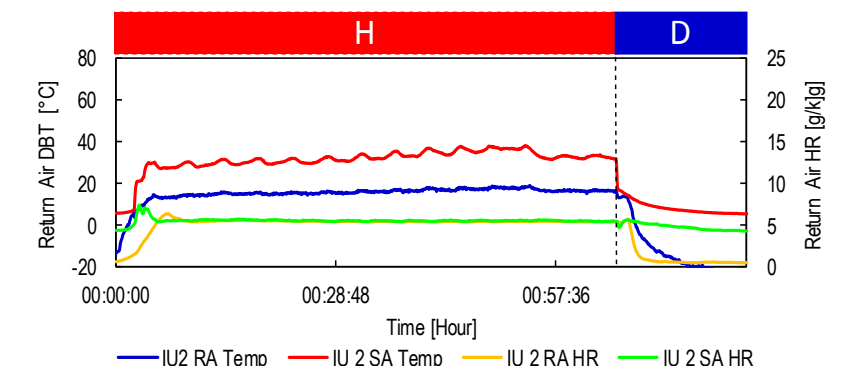

c)

Fig. 11. Results at $-11^{\circ} \mathrm{C}$ DBT and $-12^{\circ} \mathrm{C}$ WBT (H: Heating; D: Defrosting): a) Compressor speed, electric consumption and heating capacity; b) Indoor chamber 1 dry bulb temperature and humidity ratio, and; c) Indoor chamber 2 dry bulb temperature and humidity ratio.

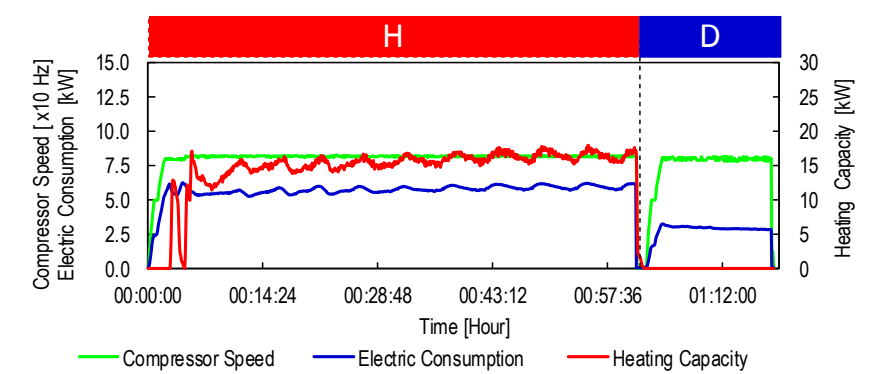

a)

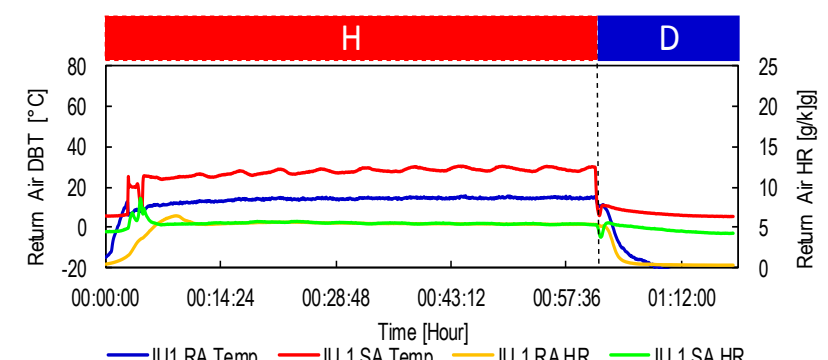

b)

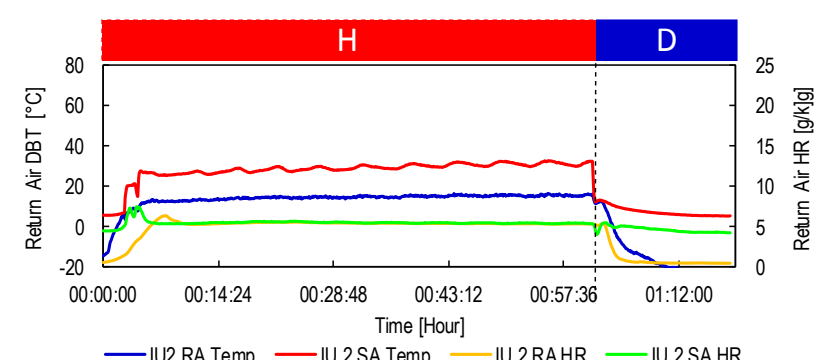

c)

Fig. 12. Results at $-15^{\circ} \mathrm{C}$ DBT and $-16^{\circ} \mathrm{C}$ WBT (H: Heating; D: Defrosting): a) Compressor speed, electric consumption and heating capacity; b) Indoor chamber 1 dry bulb temperature and humidity ratio, and; c) Indoor chamber 2 dry bulb temperature and humidity ratio.

air temperature as stated above is because of the lower outdoor air temperature and the gradual accumulation of ice in the outdoor heat exchanger which affects the heat transfer between the outdoor chamber air and the refrigerant coupled with the limitation of the system, such as the capacity of the compressor and the opening of the EEVs as explained in previous paragraph. The difference of temperature readings between the RA and SA shown in Figs. 5 to 12 during the defrosting mode is due to the location of the temperature sensors and the operation of the airflow guide vanes. During 
a)
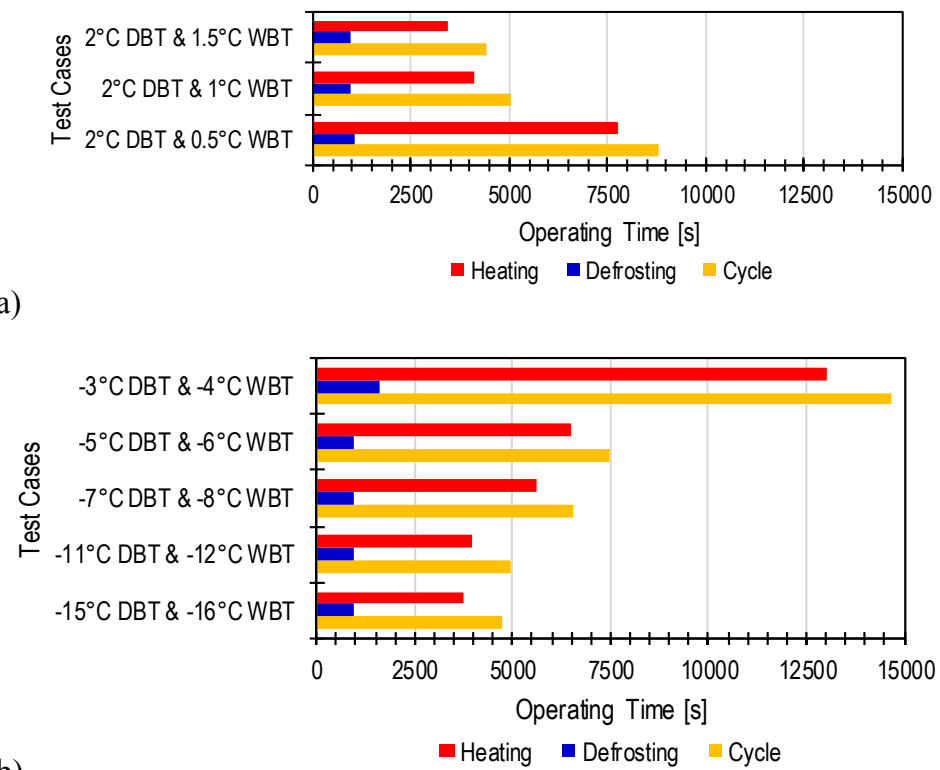

Fig. 13. Heating-defrosting cyclic operating time: a) Group 1: Constant dry bulb temperature and different wet bulb temperature, and; b) Group 2: Different dry bulb temperature and wet bulb temperature.

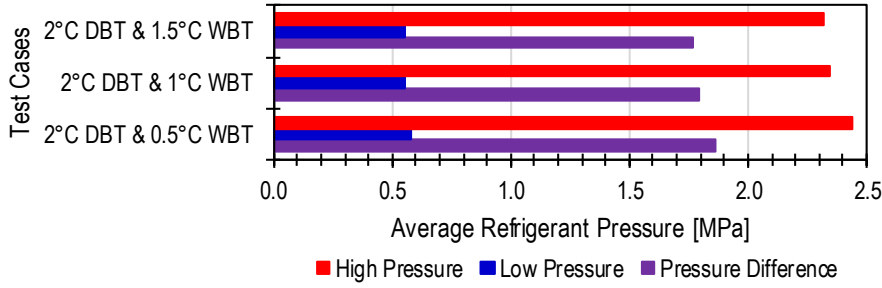

a)

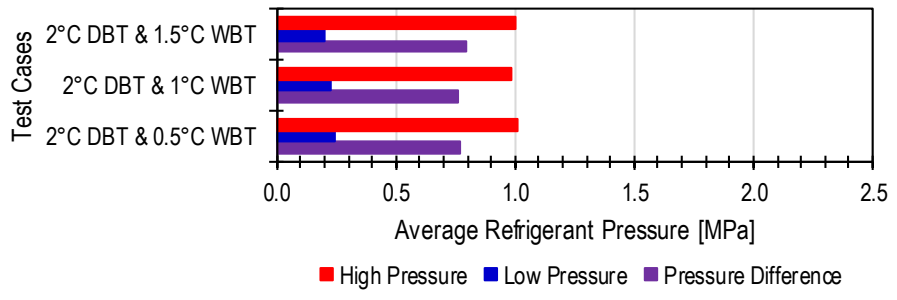

b)

Fig. 14. Group 1: Constant dry bulb temperature and different wet bulb temperature: a) Average refrigerant pressures during heating operation, and; b) Average refrigerant pressures during defrosting operation.

the defrosting operation, the guide vanes are closed; thus, the cooled air from the indoor heat exchangers passed in the RA side.

\subsection{Heating-defrosting cyclic operation time}

Figure 13 shows the heating-defrosting cycle time for the different outdoor air conditions. Figure 13a shows the cycle time for the outdoor air conditions in which the dry bulb temperature is the same, with a different wet bulb temperature (See Table 2). It shows that as the amount of moisture in the air decreases (See Fig. 3a), the heating-defrosting cycle time increases. As the moisture in the air decreases with the same dry bulb temperature, the ice formation in the outdoor unit heat exchanger takes time before the defrosting operation kicks in; thus, it results in a longer heating operation. As shown in the results, the time span for the defrosting time is almost the same due to the different time span during the heating 
operation. As explained in the previous paragraph, when the heating operation is different for different outdoor air conditions, the accumulated ice in the outdoor unit heat exchanger is expected to be almost the same. Thus, the control logic of the system operates the defrosting operation in almost the same time span.

Figure 13b shows the results for different outdoor air dry bulb and wet bulb temperatures. It shows that as the amount of moisture in the air decreases (See Fig. 3b), it takes time for the ice formation to be enough that it can cause a problem in the system operation before the control logic commands the defrosting operation to start. As shown in the results, the time of the defrosting operation is almost the same for the different test cases. The defrosting time span is based on the logic of the system in which the ice formation in the outdoor heat exchanger is almost melted and removed before the heating operation starts. With the same explanation above, the heating time depends on outdoor temperature and humidity due to the different amount of ice accumulation in the outdoor unit heat exchanger; hence, the control logic is based on the same amount of accumulated ice in the outdoor heat exchanger and thus needs the same time for defrosting.

\subsection{Refrigerant pressure}

Figure 14 shows the pressure of the refrigerant during the test cases (Test Group 1, See Table 2) with the same outdoor dry bulb temperature and different wet bulb temperature. Figure 14a shows the refrigerant pressure during the heating operation while Fig. 14b shows the refrigerant pressure during the defrosting operation. For the heating operation, the high-pressure side for the three test cases has almost the same value except that as the wet bulb temperature decreases, the high-pressure side has a little bit higher as it is an average result. For a lower wet bulb temperature, the time span for the heating operation is longer, as shown in Fig. 13a. Figure 14b shows the result of the refrigerant pressure when the system is in defrosting operation. It shows the large difference of refrigerant average pressure between the heating and defrosting operations. Hence, the large difference results in a large difference in electric consumption between the two operations as shown in Figs. 5 to 7.

Figure 15 shows the result of the refrigerant pressure for the test cases with different outdoor dry bulb temperatures and humidity (Test Group 2, See Table 2). Figure 15a shows for the result during the heating operation and Fig. 15b shows the results during the defrosting operation. In the case of the heating operation (Fig. 15a), the high refrigerant pressure decreases as the outdoor temperatures (dry bulb and wet bulb) decreases. At the same time, the lower refrigerant

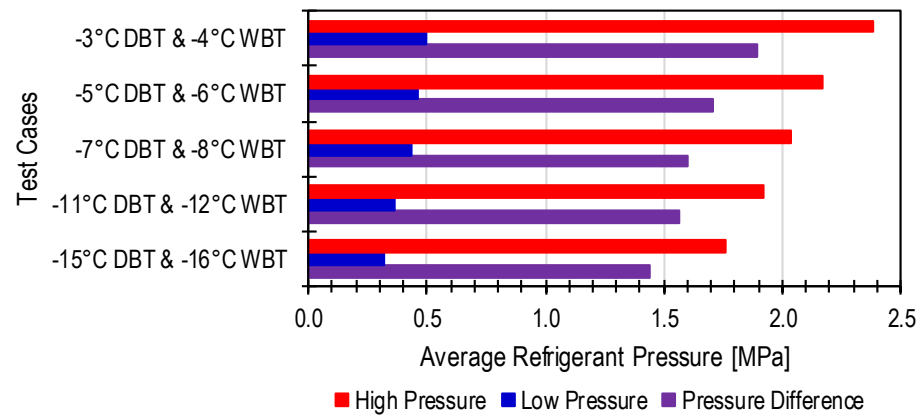

a)

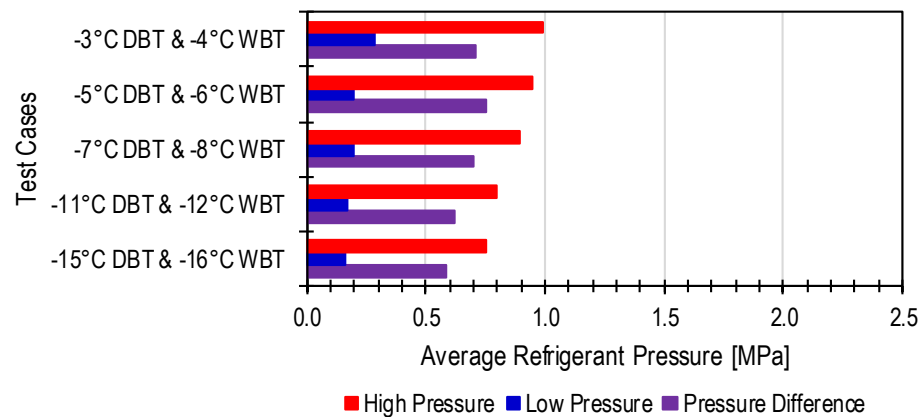

b)

Fig. 15. Group 2: Different dry bulb temperature and wet bulb temperature: a) Average refrigerant pressure during heating operation, and; b) Average refrigerant pressure during defrosting operation. 
pressure decreases as the outdoor temperatures (dry bulb and wet bulb) decrease. As the outdoor temperature decreases, the refrigerant pressure is expected to decrease to lower the refrigerant boiling point for the absorption of heat in the outdoor chamber air; hence, the refrigerant pressure decreases as the outdoor air temperature decreases. As the system has its limit in the compressor capacity and EEV valves in creating lower refrigerant pressure to reduce the refrigerant boiling temperature, the refrigerant passing the outdoor heat exchanger could not cover up the needed amount of heat to support the maintenance of the indoor units' set-point temperature. Thus, the system heating capacity becomes lower as the outdoor air temperature decreases as shown in the results in Figs. 8a to 12a.

Figure $15 \mathrm{~b}$ shows the result for refrigerant pressure during defrosting operation. It shows that the refrigerant high pressure side and low pressure side decrease as the outdoor temperature decreases. This result is due to the effectiveness of the heat transfer in the outdoor heat exchanger in melting the ice formation in the heat exchanger. When the outdoor air temperature is lower with ice formation in the outdoor heat exchanger, the refrigerant in the high pressure side with a high temperature passes into the heat exchanger to melt the ice formation which easily dissipates the heat. Thus, there is no higher build-up of refrigerant pressure as the heat transfer is more effective at a much lower air temperature with latent heat (ice melting). On the lower refrigerant pressure side, it shows that there is also a reduction of refrigerant pressure as the outdoor air temperature decreases because of lowering of the high-pressure side of the refrigerant. Based also on the results presented on Figs $8 \mathrm{~b}$ and $8 \mathrm{c}$ to $12 \mathrm{~b}$ and $12 \mathrm{c}$, the air temperature inside the indoor chambers decreases as the outdoor temperature decreases due to the reduction of heat transfer from the outdoor chamber to the indoor chamber using the refrigerant as the medium as discussed in Section 3.1.

\subsection{Performances}

Figure 16 shows the VRF air-conditioning system performances (electric consumption, heating capacity and coefficient of performance) when the system is subjected to a constant dry bulb temperature and a different wet bulb temperature shown in Table 2. It shows that the heating capacity and the electric consumption increase as the wet bulb temperature decreases or the moisture in the air reduces (Fig. 3). As the moisture in the air decreases, the heating operation time is longer, as shown in Fig. 13a. With a longer heating time, the average heating capacity is higher. With a longer heating time, the electric consumption is also expected to be higher as the electric consumption during the heating operation is higher than during the defrosting operation. Thus Fig. 16a shows the trend of results. However, the increase of electric consumption is minimal compared to the increase of heating capacity; therefore, the coefficient of performance (COP) increases as the moisture in the air or the wet bulb decreases as presented in Fig. $16 \mathrm{~b}$.

Figure 17 shows the performance results for the case of decreasing outdoor dry bulb and between bulb temperatures. Figure 17a shows the decreasing temperatures which result in the decrease of the heating capacity and electric consumption due to the system's difficulty in supporting the heat requirement of the indoor chambers as the outdoor air

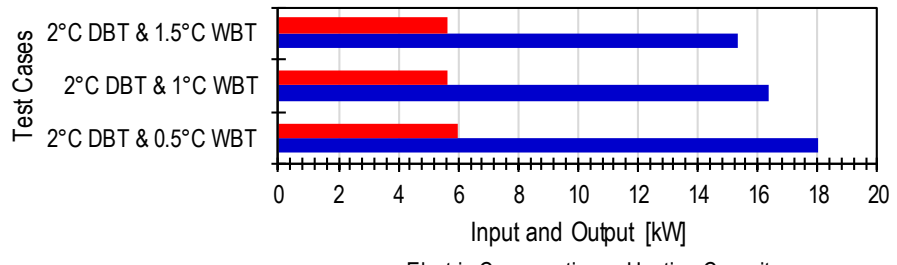

a)

- Electric Consumption $\mathbf{m}$ Heating Capacity

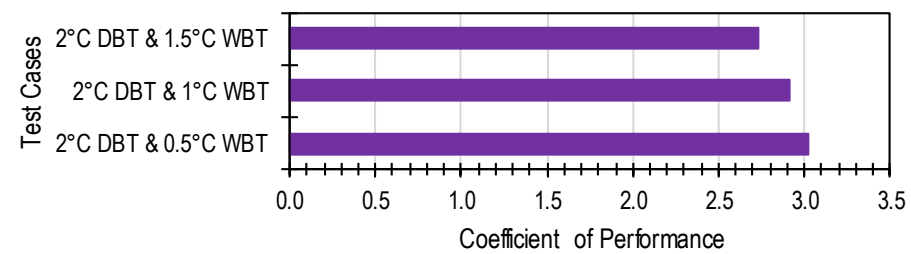

b)

Fig. 16. Group 1: Constant dry bulb temperature and different wet bulb temperature: a) Electric consumption and heating capacity, and; b) Coefficient of performance. 
a)
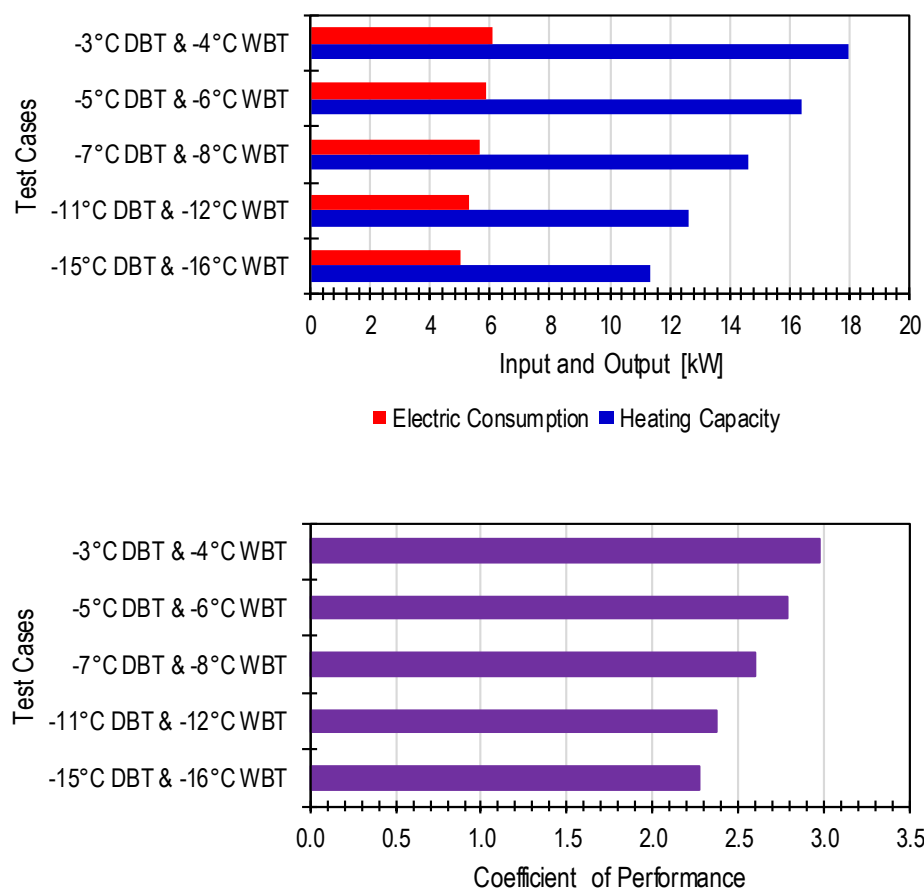

b)

Fig. 17. Group 2: Different dry bulb temperature and wet bulb temperature: a) Electric consumption and heating capacity, and; b) Coefficient of performance.

temperature decreases as presented in Figs. 8a to 12a. In addition, as shown in Figs. 8b and 8c to Fig. 12b and 12c, the air temperature in the indoor chambers falls as the outdoor air temperature decreases. Coupled with a shortened heating operation as the outdoor air temperature decreases (explained in above paragraphs), the coefficient of performance (COP) of the system decreases as the outdoor air temperature decreases as shown in Fig. 17b.

\section{Conclusion}

This paper shows the performance evaluation of the VRF air-conditioning system subjected to low outdoor air dry bulb temperatures and wet bulb temperatures when frosting or ice accumulation occurs in the outdoor unit heating exchanger during the heating mode, which resulted to the heating-defrosting cyclic operation of the system. The purpose of the study is to determine the behavior and performance of the system and the indoor thermal environmental conditions affected by the heating-defrosting cyclic operation.

Based on the results of the study, the following main conclusions are drawn:

- The different amount of moisture in the air even for the same dry bulb temperature affects the cyclic operation of the VRF air-conditioning system. As the moisture of the air increases with the same dry bulb temperature, the heating time is reduced which results in the reduction of the system's heating capacity.

- For the different outdoor air temperatures (dry bulb and wet bulb), the heating capacity of the system is reduced as the outdoor temperatures (dry bulb and wet bulb) decrease due to the system's limitation in the absorption/transfer of heat from the outdoor chamber air to the refrigerant passing the outdoor unit heat exchanger.

- The lowering of outdoor air temperatures (dry bulb and wet bulb) reduces the heating operation of the system due to the fast accumulation of the ice in the outdoor unit heat exchanger in which the system control logic kicks in the defrosting operation to melt the ice formation in the heat exchanger.

- The defrosting operation affects the stability of the indoor chambers' air temperature as the indoor units become an evaporator of the system. During the time span of the defrosting operation, the lower indoor chambers' temperature might affect the occupants in case the system is installed in a real building that has 
no back-up heater.

- As the VRF air-conditioning system is expected to encounter the heating-defrosting cyclic operation when installed in a location with a winter season, the evaluation of the system in the heating-defrosting cyclic operation is important, as presented in this study.

It is shown that in the performance evaluation of the VRF air-conditioning system at different low outdoor air dry bulb temperatures and wet bulb temperatures while the heating-defrosting operation occurs, it is important to know the behavior of the system, the electric energy consumption and the heating capacity. The results also show the importance to be considered when the system operates at a low outdoor air temperature since the heating-defrosting cyclic operation results in changes of the indoor environment temperature. The results of this and previous studies regarding the real performance of the VRF air-conditioning system and its impact on energy consumption and indoor environmental conditions at different conditions which happen during real operation is important to be considered both in energy consumption of buildings and in the maintenance of buildings required indoor thermal environment (Enteria et al., 2016a; Enteria et al., 2016b).

\section{Acknowledgement}

This research is part of the research project funded by a grant from the Japan New Energy and Industrial Technology Development Organization (NEDO) with contract number P15007. In addition, this research is part of a project entitled "Verification and Systematization of Evaluation Method of Performance for Consolidation of Energy-Conservation Standards in Building".

\section{Nomenclatures}

C Cooler

$D \quad$ Defrosting

$\dot{E} \quad$ Electric consumption $(\mathrm{kW})$

$h \quad$ Specific enthalpy $(\mathrm{kJ} / \mathrm{kg})$

$H \quad$ Heater, Heating

I Inlet Air

$n \quad$ Specified time for data

$O \quad$ Outlet Air

$P \quad$ Pressure (MPa)

$\dot{Q} \quad$ Heating Capacity $(\mathrm{kW})$

$Q \quad$ Refrigerant Flow $(\mathrm{kg} / \mathrm{s})$

$R \quad$ Return Air

$S \quad$ Supply Air
$T \quad$ Temperature $\left({ }^{\circ} \mathrm{C}\right)$

$\begin{array}{ll}T_{D} & \text { Defrosting Time }(\mathrm{s}) \\ T_{H} & \text { Heating Time }(\mathrm{s}) \\ T & \text { Temperature }\left({ }^{\circ} \mathrm{C}\right) \\ I C & \text { Indoor chamber } \\ I U & \text { Indoor unit } \\ O C & \text { outdoor chamber } \\ O U & \text { outdoor unit } \\ C O P & \text { Coefficient of performance } \\ D B T & \text { Dry Bulb Temperature }\left({ }^{\circ} \mathrm{C}\right) \\ E E V & \text { Electronic expansion valve } \\ J I S & \text { Japan Industrial Standards } \\ W B T & \text { Wet Bulb Temperature }\left({ }^{\circ} \mathrm{C}\right) \\ V R F & \text { Variable refrigerant flow }\end{array}$

Greek letter

$\alpha \quad$ Load balance ratio ( $\alpha=1$, Balanced; $\alpha<1$, Unbalanced)

\section{References}

Building Energy Standard of Japan, Part 1. Non-residential buildings. Method for calculations and judgments in conformity. Supervised by National Institute of Land and Infrastructure Management (NILIM) and Building Research Institute (BRI) (2013) (in Japanese).

Enteria, N., Yamaguchi, H., Miyata, M., Sawachi, T. and Kuwasawa, Y., Performance Evaluation of the Variable Refrigerant Flow (VRF) Air-Conditioning System Subjected to Partial Loadings at Different Outdoor Air Temperatures, JSME Journal of Thermal Science and Technology, Vol. 11, No. 2, (2016a), pp. 1-11. DOI: 10.1299/jtst.2016jtst0013

Enteria, N., Yamaguchi, H., Miyata, M., Sawachi, T. and Kuwasawa, Y., Performance evaluation of the variable refrigerant flow (VRF) air-conditioning system subjected to partial and unbalanced thermal loadings, JSME 
Journal of Thermal Science and Technology, Vol. 11, No. 1 (2016b), pp. 1-13.

DOI: $10.1299 /$ jtst.2016jtst0029

Goetzel, W., Variable refrigerant flow systems. ASHRAE Journal Vol. 49, No.4 (2007), pp. 24-31.

Horie, H. and Hihara, E., Study on annual performance of room air conditioners under part load conditions. Proceedings of International Refrigeration and Air Conditioning Conference (2012), Paper No. 2537.

Japan Industrial Standard. JIS B 8616:2015, Package air-conditioners. Japanese Standard Organization (2015) (in Japanese).

Japan Industrial Standard. JIS B 8615-1:1999, Ducted air-conditioners and air-to-air heat pumps testing and rating for performance. Japanese Standard Organization (1999) (in Japanese).

Watanabe, C., Nagamatsu, K., Nakayama, H., Hirota, M. and Ohashi, E., Performance characteristics of multi-type airconditioners for building under partial thermal load operations. Proceedings of the International Symposium on EcoTopia Science (2007), pp. 248-254.

Watanabe, C., Hirota, M., Ohashi, E., Nagamatshu, K. and Nakayama, H., Evaluation of annual performance of multitype air-conditioners for buildings (Comparison of EHP and GHP). Proceedings of the International Conference on Power Engineering (2009), Paper No. C301. 